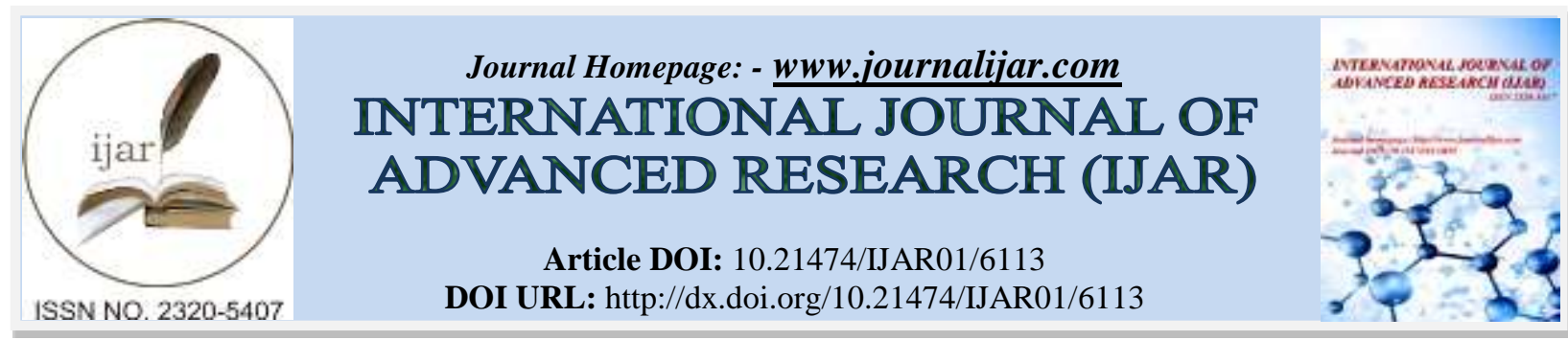

RESEARCH ARTICLE

\title{
RELATIONSHIP BETWEEN OBESITY AND LOW BACK PAIN AMONG ADOLESCENTS AT HAIL TERRITORY-K. S. A.
}

\author{
Ahmed Abdelmoniem Ibrahim, Ph D. PT ${ }^{1}$, Mohamed raffat Mohamed atteya. Ph. D. PT $^{2}$, Rania Fathy \\ Mohamed Youssef, Msc. PT ${ }^{3}$, Saleh Yahay AITayar physiotherapy student ${ }^{4}$ and Abdullah Salim Hamad \\ Albuwait physiotherapy student ${ }^{5}$. \\ 1. Physiotherapy Department, Cairo university hospitals, Cairo; Egypt pox -11562 . \\ 2. $\quad \mathbf{2 , 3 , 4 5}^{\mathbf{3}}$ Physical Therapy Department, College of Applied medical sciences, University of Hail-KSA -pox.
}

\section{Manuscript Info}

Manuscript History

Received: 20 October 2017

Final Accepted: 22 November 2017

Published: December 2017

Keywords:-

Low back pain, obesity ,Adolescents

\section{Abstract}

Objective: Low back pain (LBP) is a common in many countries. Its prevalence is not yet verified in Saudi Arabia. The objectives of this study were to investigate the prevalence of LBP among obese adolescents in Hail city; Method: A cross-sectional study done on population of 200 adolescence aged 20 to 25 years were selected from Hail city K.S.A. Data were collected through personal interviews using a structured questionnaire and analyzed using SPSS software. Results: about $68 \%$ of obese adolescence have low back pain .Conclusions: This study was indicated that an association exists between obesity and LBP. The main route for prevention of LBP among adolescence is likely to lie in Limit of Obesity, Good posture and we Should raise awareness about the prevalence of lower back pain among these students

Copy Right, IJAR, 2017,. All rights reserved.

\section{Introduction:-}

Low back pain (LBP) is the most common chronic pain conditions. Untreated, it can lead to personal suffering as well as economic consequences at both the social and individual level ${ }^{[1]}$.

LBP is defined as acute when lasting less than 6 weeks, sub-acute when lasting between 6 weeks and 3 months, and chronic when lasting more than 3 months. In addition, while many patients with LBP recover quickly, LBP commonly follows a recurrent course, with exacerbations occurring over time.

Generally, lifetime prevalence rates of LBP are estimated to be 70 to 85 percent and point prevalence rates average around 30 percent $^{[2]}$.

Risk factors for the presence and severity of LBP include both sociodemographic factors, such as age as well as lifestyle factors, such as smoking and physical conditioning ${ }^{[3] . ~[4]}$,

Many studies investigated the risk factors associated with low-back pain in adolescents such as age, gender, positive parental history of treatment for low-back pain, psychosocial events, frequency of sports, and other factors ${ }^{[7]}$. One study investigated the contribution of vitamin D deficiency as a cause for idiopathic chronic low back pain in Saudi Arabia ${ }^{[8]}$. 
Low back pain in adolescents is perceived to be uncommon in the clinic setting. However, some studies have suggested that it is a relatively common feature, demonstrated disability and interference with daily activities in this age group ${ }^{[5]}$. Studies of LBP in this age group are of particular importance, as back pain that occurs initially during this time may forerunner the onset of intermittent or chronic pain in adulthood ${ }^{[6]}$

Obesity is a growing public health concern. Globally, the number of overweight or obese people is dramatically increasing, Obesity contributes substantially to the burden of chronic medical conditions, and these medical conditions place a high economic burden on the health care systems ${ }^{[9]}$. Obesity may have both biomechanical and meta inflammatory effects on the spine. ${ }^{[10]}$.

The aim of our study was to investigate the relationship between obesity and LBP among young obese adolescents

\section{Subjects, Materials and Methods:-}

Our study consists of 200 obese adolescents selected from Hail city and age between (20 to 25).

The current study is a cross sectional study, a self-administered questionnaire was used for data collection. The Data was collected from subjects in their place of work. The Questionnaire consists of three sections: The first section is demographic data, age, height, weight, gender. The second section will is history of LBP, e.g. onset of pain or injury, duration of LBP. Finally the third section is work setting and effect of LBP on daily activities, limitations due to LBP, as well as the presence of current LBP and rating the intensity LBP on a scale of 0 (no pain) to 10 ( maximum pain) that represented a numerical system of $10 \mathrm{~cm}$ on a visual analogue scale.

\section{Data Analysis:-}

Data were processed using the Statistical Package for Social Sciences (SPSS) computer software. Differences were considered significant $P$ value. was $<0.05$. The Pearson chi-square test was used to assess the extent of association between two categorical variables. In case of skewed non-normal variables like rating score, the median, 2.5 th and 97.5th percentiles were used as measures of location and variation. The Mann-Whitney U nonparametric test was used to assess the significance of the difference between two quantitative variables.

\section{Results:-}

The Results indicate that an association exists between obesity and LBP prevalence .NB: from 1 to 6 are the grade of each task see the appendix 
Table 1:- Show The Correlation Frequency And Percentage Of Pain With Various Activities.

\begin{tabular}{|c|c|c|c|c|c|c|c|}
\hline Activities & & 1 & 2 & 3 & 4 & 5 & 6 \\
\hline \multirow[b]{2}{*}{ Pain Intensity } & Frequency & 58 & 70 & 73 & 20 & 7 & 5 \\
\hline & Percentage & 24.89 & 30.04 & 31.33 & 8.58 & 3.00 & 2.15 \\
\hline \multirow{2}{*}{$\begin{array}{c}\text { Personal Care (Washing, } \\
\text { Dressing etc.) }\end{array}$} & Frequency & 50 & 93 & 58 & 20 & 2 & 10 \\
\hline & Percentage & 21.46 & 39.91 & 24.89 & 8.58 & 0.86 & 4.29 \\
\hline \multirow[b]{2}{*}{ Lifting } & Frequency & 40 & 86 & 61 & 20 & 21 & 5 \\
\hline & Percentage & 17.17 & 36.91 & 26.18 & 8.58 & 9.01 & 2.15 \\
\hline \multirow[b]{2}{*}{ Walking } & Frequency & 37 & 80 & 57 & 43 & 12 & 4 \\
\hline & Percentage & 15.88 & 34.33 & 24.46 & 18.45 & 5.15 & 1.72 \\
\hline \multirow[b]{2}{*}{ Sitting } & Frequency & 40 & 76 & 83 & 17 & 14 & 3 \\
\hline & Percentage & 17.17 & 32.62 & 35.62 & 7.30 & 6.01 & 1.29 \\
\hline \multirow[b]{2}{*}{ Standing } & Frequency & 49 & 88 & 65 & 19 & 8 & 4 \\
\hline & Percentage & 21.03 & 37.77 & 27.90 & 8.15 & 3.43 & 1.72 \\
\hline \multirow[b]{2}{*}{ Sleeping } & Frequency & 31 & 86 & 53 & 30 & 24 & 9 \\
\hline & Percentage & 13.30 & 36.91 & 22.75 & 12.88 & 10.30 & 3.86 \\
\hline \multirow[b]{2}{*}{ Social Life } & Frequency & 100 & 87 & 42 & 4 & 0 & 0 \\
\hline & Percentage & 42.92 & 37.34 & 18.03 & 1.72 & 0.00 & 0.00 \\
\hline \multirow[b]{2}{*}{ Traveling } & Frequency & 59 & 77 & 40 & 34 & 19 & 4 \\
\hline & Percentage & 25.32 & 33.05 & 17.17 & 14.59 & 8.15 & 1.72 \\
\hline \multirow{2}{*}{$\begin{array}{c}\text { Employment/Homemaki } \\
n g\end{array}$} & Frequency & 90 & 76 & 30 & 18 & 15 & 4 \\
\hline & Percentage & 38.63 & 32.62 & 12.88 & 7.73 & 6.44 & 1.72 \\
\hline
\end{tabular}


Fig 1:- Correlation Frequency And Percentage Of Pain With Various Activities

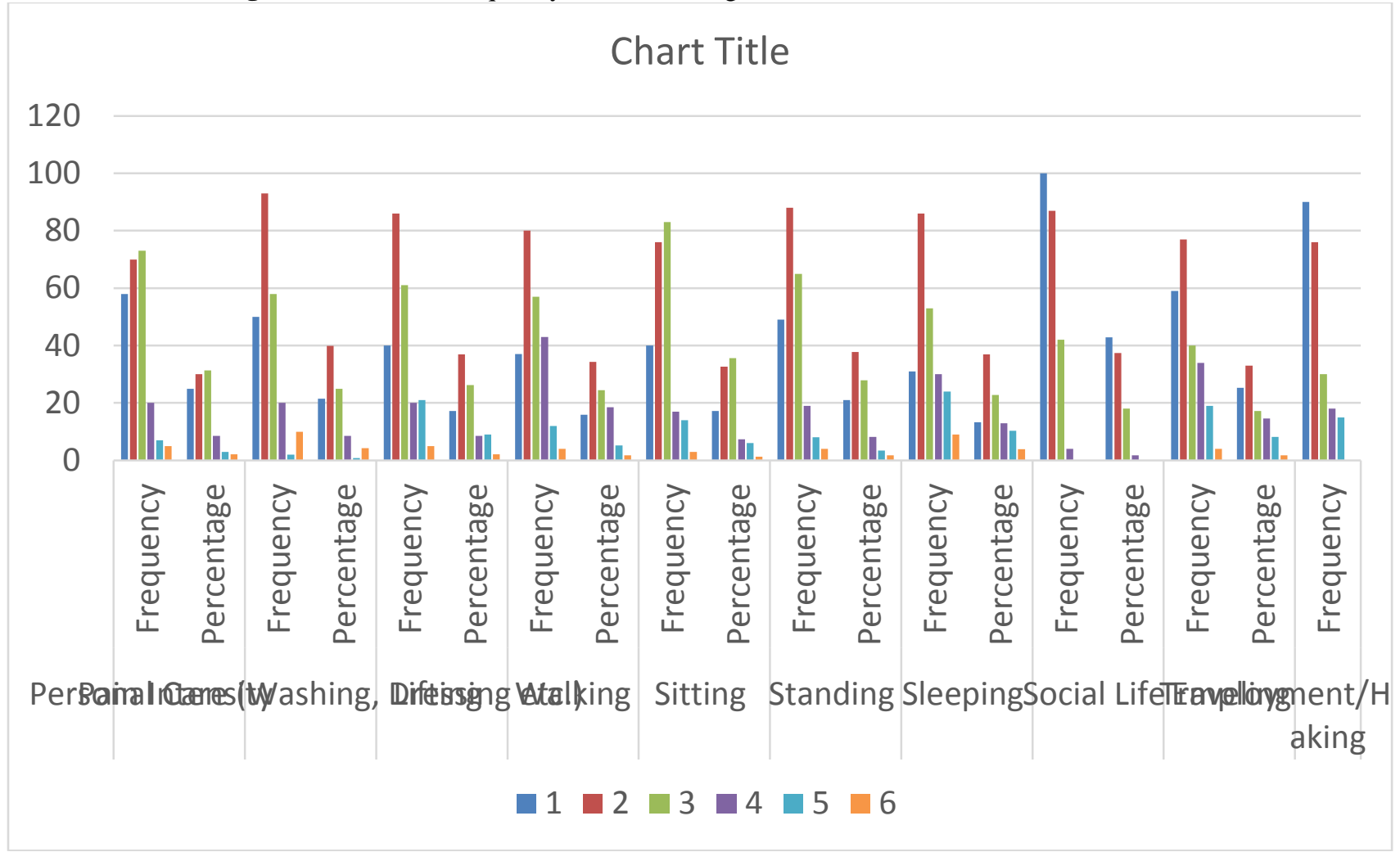

Discusion:-

Number of studies have been published that attempt to the relationship between LBP and obesity, Some crosssectional studies conducted in general populations have found no relation between LBP and obesity, while others have found a positive relation between the two ${ }^{[11]}$. Several studies have found LBP to be independently associated with obesity $(\mathrm{N}>5,000)$ cross-sectional samples of adults from the general population ${ }^{[12]}$.

A large nationwide study of 15,974 patients with spine disorders found that higher BMI in this population was associated with increased disability, more pain, and more comorbidities than in the non-obese patient ${ }^{[13]}$.

Combined, studies such as these that report a positive association between obesity and LBP suggest a possible doseresponse relationship between the two such that increasing prevalence of LBP occurs with increasing BMI. [14].

Several recent reviews have attempted to address the relationship between LBP and weight. Generally, these reviews have suggested that, while a relationship between overweight/obesity and LBP may indeed exist, the current state of science lacks evidence clearly establishing a direct relationship between the two. Garzillo and Garzillo, in an early review of seven studies, found no evidence to support the recommendation of weight loss to treat LBP, though they did state that some evidence of a correlational relationship existed between LBP and obesity ${ }^{[15] .}$

Finally, inconclusive findings may point to the importance of other mediating factors that affect the relationship between weight and pain. Indeed, as has been shown in some of the research to date, the relationship between obesity and LBP may not be directly causal. Some of the factors that could function as possible mediators and need further investigation include sex, age, height/stature , distribution of body fat and waist circumference , socioeconomic factors, and lifestyle factors (smoking, and physical activity . 


\section{Conclusion:-}

The study revealed high prevalence of lower back pain among obese adolescents in hail. Low back pain has been studied in different places in the world. This Study has shown that low back pain is particularly common in obese adolescents. about $68 \%$ of obesity adolescents have low back pain. The results are in agreement with other studies.

\section{Recommendations:-}

The relationship between low back pain and obesity is undeniable and unwanted, but not inseparable. Losing weight can help to prevent back pain, reduce back pain, improve treatment results and create a better quality of life. For those carrying a serious amount of weight, bariatric surgery would be a logical first step towards relieving low back pain. Although not everyone who is overweight has low back pain and not everyone with low back pain carries too much weight, body weight does tend to matter. It matters not only because of sheer mass and load but also because of what's happening on the inside of your body too. Don't take your weight too lightly when it comes to dealing with your low back pain. The link between obesity and low back pain may be stronger than you realize.

\section{References:-}

1. Manek NJ, MacGregor AJ. Epidemiology of back disorders: Prevalence, risk factors, and prognosis. Curr Opin Rheumatol. 2005;17(2):134-40.

2. Andersson GB. Epidemiological features of chronic low-back pain. Lancet. 1999;354(9178):581-85.

3. Stranjalis G, Tsamandouraki K, Sakas DE, Alamanos Y. Low back pain in a representative sample of Greek population: Analysis according to personal and socioeconomic characteristics. Spine. 2004;29(12):1355-60

4. Kaila-Kangas L, Leino-Arjas P, Riihimaki H, Luukkonen R, Kirjonen J. Smoking and overweight as predictors of hospitalization for back disorders. Spine. 2003;28(16): 1860-68.

5. Bejia, I., N. Abid, K. BenSalem, M. Touzi and N. Bergaoui, 2006. Reproducibility of a low back pain questionnaire in Tunisian adolescents. Clinical Rheumatology, 25(5): 715-720.

6. Harreby, M., K. Neegaard, G. Hesselsce and J. Kjer, 1995. Are radiological changes in thoracic and lumbar spine of adolescents risk factors for low back pain in adults? Spine, 20(21): 2298-2302.

7. Halalsheh, M., M. Tarawneh and Z. Mahadine, 2000. The association of low back pain with obesity in one of the primary health care centers. Bahrain Medical Bulletin, 22(1): 1-5.

8. Al Faraj, S. and K. Al Mutairi, 2003. Vitamin D Deficiency and Chronic Low Back Pain in Saudi Arabia. Spine, 28(2): 177-179.

9. Haslam DW, James WP. Obesity. Lancet. 2005;366(9492): 1197-1209.

10. Shiri R, Solovieva S, Husgafvel-Pursiainen K, et al. The role of obesity and physical activity in non-specific and radiating low back pain: the Young Finns study. Semin Arthritis Rheumatism. 2013;42:640-650.

11. Andersen RE, Crespo CJ, Bartlett SJ, Bathon JM, Fontaine KR. Relationship between body weight gain and significant knee, hip, and back pain in older Americans. Obes Res. 2003;11(10):1159-62.

12. Webb R, Brammah T, Lunt M, Urwin M, Allison T, Symmons D. Prevalence and predictors of intense, chronic, and disabling neck and back pain in the UK general population. Spine. 2003;28(11):1195-1202. [PMID: 12782992]

13. Fanuele JC, Abdu WA, Hanscom B, Weinstein JN. Association between obesity and functional status in patients with spine disease Spine.2002;27(3):306-12. [PMID: 11805697]

14. Leboeuf-Yde C, Kyvik KO, Bruun NH. Low back pain and lifestyle. Part II-Obesity. Information from a population-based sample of 29,424 twin subjects. Spine. 1999; 24(8):779-84. [PMID: 10222529]

15. Garzillo MJ, Garzillo TA. Does obesity cause low back pain? J Manipulative Physiol Ther. 1994;17(9):6014.[PMID: 7884330] 